\title{
The impact of a multi-fruit wine on serum urea, albumin and total tissue protein levels in rats
}

\author{
Asuk A. $\mathrm{A}^{1}$, Dasofunjo $\mathrm{K}^{1}$, Ofem O. E ${ }^{2}$, Akpanyung E.O. ${ }^{3}$ \\ ${ }^{I}$ Department of Medical Biochemistry, Faculty of Basic Medical Sciences, Cross River University of \\ Technology, Okuku-campus, P.M.B 1123 Calabar, Cross River State, Nigeria. \\ ${ }^{2}$ Department of Physiology, Faculty of Basic Medical Sciences, University of Calabar, Calabar, Cross River \\ State, Nigeria \\ ${ }^{3}$ Department of Biochemistry, Faculty of Basic Medical Sciences, University of Uyo, Uyo, Akwa Ibom State, \\ Nigeria.
}

\begin{abstract}
This present research is aimed at evaluating the impact of a multi-fruit wine obtained from a blend of five fruits on serum urea, albumin and total tissue protein in albino Wistar rats. Seventy (70) albino Wistar rats were randomly divided into seven (7) study groups of ten rats per group $(n=10)$. The animals were placed on either low (corresponding to four standard drinks) or high (six standard drinks) doses of multi-fruit wine with additives (MFWA) or plain wine (MFWP), low doses of red wine or cashew wine. All animals had free access to normal rat feed and drinking water. The feeding regimens lasted for 2 weeks. The result showed no significant difference $(p \geq 0.05)$ in serum urea, protein homogenate and supernatant tissue protein among groups administered the multi-fruit wine. High dose of multi-fruit wine plain (H-MFWP) and low dose of red wine (STD 1) increased serum albumin concentrations significantly $(p<0.05)$ compared with the control. Results of the investigation showed no adverse alteration in the biochemical parameters of the experimental animals following administration of the multi-fruit wine, suggesting that the multi-fruit wine can be used alongside other therapeutic purposes associated with the maintenance of the kidney and liver function.
\end{abstract}

Key words: albumin, multi-fruit wine, standard wines, tissue protein, urea.

\section{Introduction}

It has been estimated that the medicinal use of wine dates back to 2200 B.C, making it the oldest known medicine [1]. Historically, wine has been used as an antiseptic, a painkiller, and to treat dermatological conditions and digestive disorders $[1,2]$.

The mechanisms responsible for the healthful effects of wine are extremely complex. Both the alcohol and the polyphenol components have been extensively studied and there is controversy over which component is more important $[3,4]$. It has been well documented that a moderate intake of alcoholic beverages produces positive effects on antioxidants, lipids, and platelets [5]. Other studies provide evidence that wine demonstrates beneficial properties that are independent of the presence of alcohol, which has been attributed to the polyphenol content of wine $[6,7]$.

Although, the positive health effects of wine are many, the evidence is clear that these benefits are the highest for those who drink red wine in moderation (two drinks per day for men and one drink per day for women) over extended periods of time. Three or more drinks per day may increase the risk of neurodegeneration, depressive disorders, and obesity, weakening of bones, hypertriglyceridemia, heart disease, hypertension, stroke, breast cancer, suicide, and injuries [8]. Wine consumption in any amount is contraindicated for pregnant women, children, patients with liver disease, and in combination with certain medications [2].

Red wine has been shown to decrease bioavailability of cyclosporine, nifedipine (an antihypertensive drug) and lovastatin, an antilipemic drug $[9,10]$ but increase the bioavailability of niacin another anti-lipemic [10] or increase the concentration of a calcium channel blocker felodipine [11].

In one study, drinking two glasses of red or white wine in the evening did not significantly increase the risk of suppression of coagulation function the next day [12]. Wine has been associated with various impacts on some biochemical compounds. Multi-fruit wine by extension is wine made from fruits other than grape and classified as fruit wines [13]. The interactions exhibited by wines made from sources other than grape are of imminent interest especially in the part of the world where grape is not grown. Therefore knowing the effect of multi-fruit wine on some biochemical parameters using standard wines (red wine and cashew wine) as guides in this research on albino rats is of particular interest. 


\subsection{Preparation of Multi-Fruit Wine}

\section{Materials and Methods}

The Multi-fruit wine was prepared from a blend of five fruit extract namely, Lycopersicon esculentum (tomato), Citrus sinensis (orange), Citrus lemon (lemon), Chrysophyllum africanum (African star apple) and Prunus amygdalus var dulcis (almond). The samples so collected were processed for the production of the multi-fruit wine as described by Asuk et al. [14]. The fermentation media was obtained and 'must' prepared. Briefly, 20 balls of tomato weighing $1 \mathrm{~kg}$ were thoroughly washed with clean water and ground with a blender, $70 \mathrm{~g}$ of the almond nut was weighed and also ground with a blender, while 20 balls of orange weighing $3 \mathrm{~kg}, 10$ balls of lemon weighing $800 \mathrm{~g}$ and 20 balls of African star apple weighing $2 \mathrm{~kg}$ were all squeezed out manually to obtain their respective juice and then covered in pre-sterilized containers. The respective fruit blends of tomato, orange, almond, African star apple and lemon were all mixed together in a 20 litre fermentation jar which was filled to the mark with distilled water. Seven $(7 \mathrm{~g})$ of instant baker's yeast, $3.06 \mathrm{~g}$ of sodium metabisulphite, $3.45 \mathrm{~g}$ of ammonium sulphate were all added and finally, $3.90 \mathrm{~kg}$ of granulated sugar was also added to induce fermentation by the baker's yeast. The specific gravity of the resultant mixture in the fermentation jar containing the above mixture of the must was taken at 1.085 at the start of the experiment. On the sixth day of the experiment, the primary fermentation stopped when the specific gravity dropped to 1.000 and remained unchanged. The young fruit-wine was racked (decanted) every week after the primary fermentation stopped, to separate sediments of the wine in order to achieve clarity. The multi-fruit wine was bottled and allowed to age for about six (6) months. It was later stored in the refrigerator at $10-15^{\circ} \mathrm{C}$ until when required for use. This method is a subject of an earlier report described by Asuk et al. [14].

To four (4) liters of the multi-fruit wine were added $0.4 \%$ citric acid, $6 \%$ caramel, $0.003 \%$ potassium metabisulphite and 3\% sugar. The wine was then filtered (using a Whatman No. 1 filter paper) and bottled to obtain a standard wine referred to as 'wine with additives'. Another set of wine not treated with additives was left as plain wine. The standard wines vis-à-vis cashew wine and red wine were obtained from CRIN Ibadan and Rabana Supermarket, Calabar respectively. The multi-fruit wine was then characterized or standardized, the alcohol content was determined as $12 \%$ with a corresponding value for the red and cashew wines (which were indicated on their bottles). The phytochemical screening was also done for all the wine samples (including red and cashew wines) as indicated in Asuk et al. [14].

\subsection{Experimental Animals}

A total of seventy (70) albino Wistar rats used for this study were obtained from the animal house of the Faculty of Agriculture, University of Calabar, Calabar, Cross River State, Nigeria. The study was approved by the Animal House Committee of the University. All conditions of animal use were also as approved by United States National Institute of Health (NIH) guide for Care and Use of Laboratory Animals and in accordance with the recommendation of IASP [15] The animals were reared with a commercial stock diet guinea feeds rat chow (Guinea Feeds Nigeria Ltd, Benin) until they weighed $100-250 \mathrm{~g}$ when they were used for the experiment. They were housed in wooden box cages (size $1 \mathrm{~m} \times 0.5 \mathrm{~m} \times 0.2 \mathrm{~m}$ ). The beddings were changed regularly. The animals were kept in the Department of Biochemistry animal house under adequate ventilation with a temperature and relative humidity of $26 \pm 2{ }^{\circ} \mathrm{C}$ and $46 \%$ respectively to acclimatize for 7 days. Feed and water were provided ad libitum.

\subsection{Experimental Design}

This involved animal experimentation and treatment with mixed fruit wine obtained from a blend of tomato, orange, African star apple, lemon and almond to determine some physiochemical changes.

Seventy (70) albino Wistar rats were randomly assigned on the basis of body weight and sex into 7 study groups of 10 rats per group and treated according to the doses schedule below:

Group I - C: Control group given normal diet + water only

Group II - L- MFWA: Low dose of wine produced with additives administered at $5.71 \mathrm{ml} / \mathrm{kg}$ body weight of experimental rat

Group III - H - MFWA: High dose of wine produced with additives administered at $8.57 \mathrm{ml} / \mathrm{kg}$ body weight of experimental rat

Group IV - L - MFWP: Low dose of wine produced without additives administered at $5.71 \mathrm{ml} / \mathrm{kg}$ body weight of experimental rat.

Group V-H - MFWP: High dose of wine produced without additives administered at $8.57 \mathrm{ml} / \mathrm{kg}$ body weight of experimental rat 
Group VI - STD 1: Low dose of standard red wine administered at 5.71/kg body weight of experimental rat

Group VII - STD 2: Low dose of standard cashew wine administered at $5.71 \mathrm{ml} / \mathrm{kg}$ body weight of experimental rat

The dose levels used for the animal wine administration was based on the AGDHA on 'Standard drinks guide' for levels considered to be low-risk for a 70kg man [16]. The experimental regimes lasted for 2 weeks.

The body weights were monitored every two days throughout the duration of the experiment, all the experimental animals was finally denied access to feed for 18 hours prior to sacrifice.

\subsection{Collection of Blood and Liver Samples}

Blood samples were collected via cardiac puncture under chloroform (5\%) inhalation. Blood samples were placed in sterile EDTA sample bottles and briskly agitated to present clotting. The samples were used for the estimation of urea, albumin. Liver samples were also collected, weighed, homogenized and used for the estimation of tissue protein.

\subsection{Estimation of Urea, Albumin And Total Tissue Protein}

Serum urea was determined by the use of Randox Laboratory reagent kit method. In principle, urea in serum is hydrolysed to ammonia in the presence of urease.

The ammonia is then measured photometrically by Berthelot's reaction

Urea $+\mathrm{H}_{2} \mathrm{O}$ Urease $2 \mathrm{NH}_{3}+\mathrm{CO}_{2}$

The albumin and tissue proteln cortentration was estimated by biuret method using Dialab reagent kit method [17].

Cupric ions, in an alkaline medium, interact with protein peptide bonds resulting in the formation of a colour complex known as biuret. Biuret absorb light maximally at $540 \mathrm{~nm}$ and the absorbance measured spectrophotometrically is used in the quantification of protein.

\subsection{Statistical Analysis}

Data obtained were subjected to statistical analysis using standard computerized Statistical Package for Social Science (SPSS) version 11. ANOVA, post hoc (least standard deviation multiple comparison) test were carried out and values expressed as mean \pm SEM. Statistical significance was accepted at $p<0.05$.

\section{Results}

The values of serum urea, albumin and tissue proteins of albino Wistar rats are shown in figures 1 to 2 . The values of serum urea showed no significant $(\mathrm{p} \geq 0.05)$ difference among the groups, Fig 1 .

The values of serum albumin showed significant $(p<0.05)$ increase in H-MFWP and STD1 when compared with the normal control, serum albumin in H-MFWA was significantly $(p<0.05)$ lower compared with the standard control group STD1, whereas H-MFWP had significantly $(\mathrm{P}<0.05)$ higher serum albumin levels when compared to STD2, Fig 2.

The tissue proteins were done for both the whole homogenate and the supernatant. The values of the whole homogenates and supernatant of tissue proteins of all the test groups were not significant $(\mathrm{P} \geq 0.05)$ compared with the normal control, but the whole homogenates of H-MFWP and the supernatants of L-MFWA, L-MFWP and H-MFWP showed significant $(\mathrm{P}<0.05)$ increase when compared with STD2, Fig 2. 


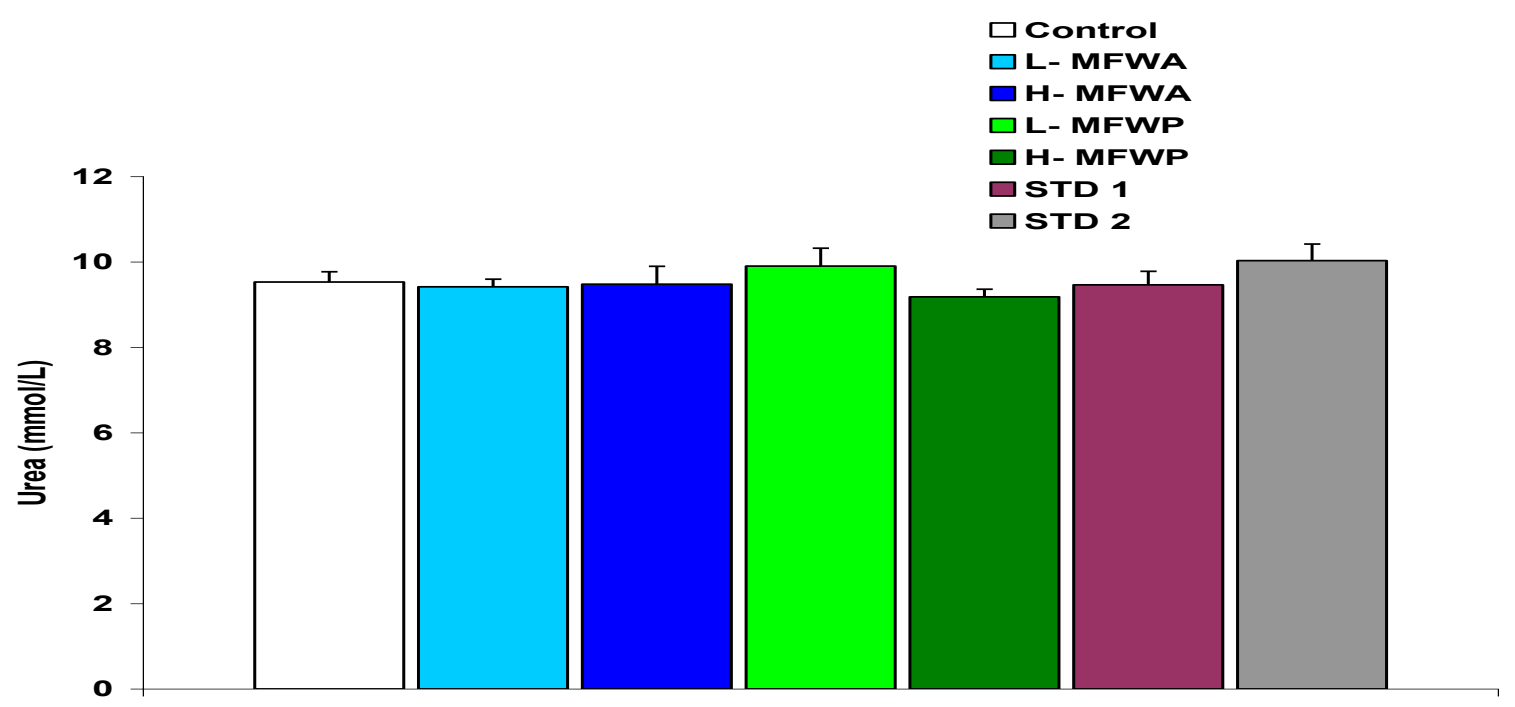

Values are mean \pm SEM, $\mathrm{n}=10$

Fig 1: Urea concentrations of different experimental groups of rats

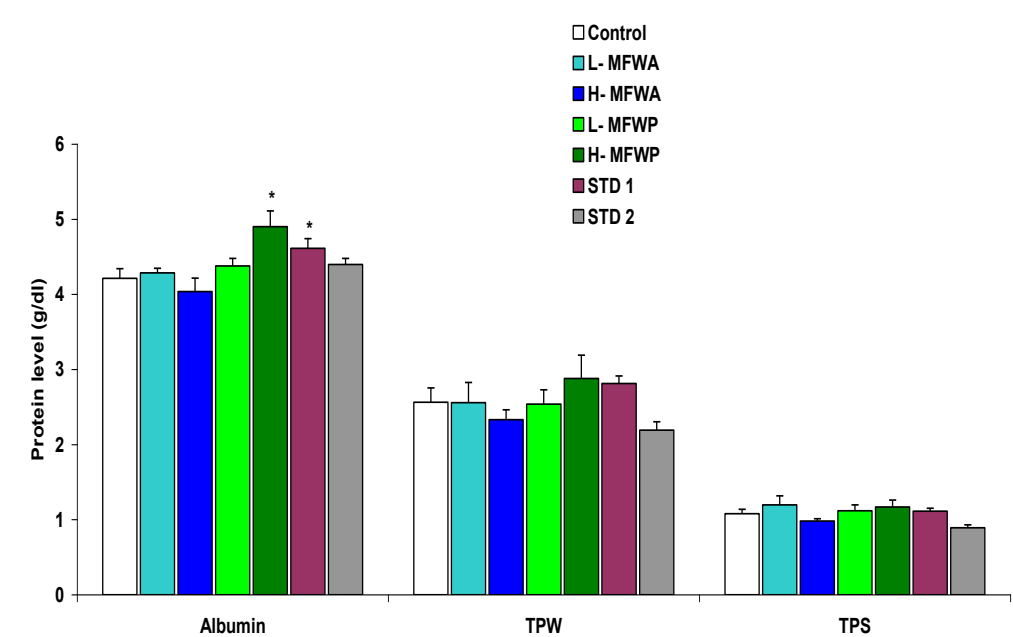

Values are mean \pm SEM, $\mathrm{n}=10 . * \mathrm{p}<0.05$

Fig 2: Albumin, whole protein homogenate (TPW) and supernatant tissue protein (TPS) of different experimental groups of rats

\section{Discussion}

The biochemical indices monitored vis-à-vis serum urea, albumin and tissue protein are helpful biomarkers in the investigation, diagnosis or prognosis of diseased conditions, hence the need to determine the effect of the multi-fruit wine on albino rats' population.

Urea is a non-protein nitrogenous compound formed as an end product of protein metabolism and must be removed from the body to ensure continued normal protein metabolism in the cells. During renal failure, the concentration of serum urea in humans can rise to as high as 10 times the normal within 1 to 2 weeks [18]

The urea values of the albino rats' population showed no significant difference when compared with the control. This is an indication that there was no renal dysfunction.

Albumin is a soluble plasma protein which is formed in the liver with the aim of providing colloid osmotic pressure in the plasma and prevents plasma loss from the capillaries [18]. Albumin is the protein with the highest concentration in the plasma. It transports many molecules in the blood. It prevents the fluid in the blood from leaking out the tissue [19]. Albumin levels are decreased in chronic liver disease such as cirrhosis or nephrotic syndrome.

The population of albino wistar rats showed no significant difference in serum albumin concentration; however H-MFWP and STD1 of the population showed significant increase in serum albumin compared with the control. The significant increase in these groups may have been as a result of dehydration or reduced intake of water, therefore the increased formation of albumin by the liver to prevent plasma loss, indication that the 
multi-fruit wine may promote good functioning of the liver or possess a hepatoprotective role and may help calcium in the blood stream regulate the movement of water in the blood stream into body tissue [20].

Tissue proteins are important in maintaining body mass and tissue structure of organs and could be increased during growth and decreased during starvation, wasting or protein catabolism. The increase or decrease in tissue proteins on administration of the multi-fruit wine, may have been influenced by several factors which include the secretion of growth hormones, particularly glucocorticoids and phytochemicals signaling $[18,21,22]$.

The increase in glucocorticoids secretion promotes increase in liver tissue production of proteins and other metabolites, while the decreased secretion encourages ketogenesis and gluconeogenesis [18] probably as a result of organ preference formation of proteins in the muscles.

\section{Conclusion}

This research addressed the implications of multi-fruit wine administration when sex is ignored. It looked at what will generally happen in the human population with the use of rats as a model without sex differentiation. The biomarkers applied in this research vis-à-vis urea, albumin and tissue protein homogenates showed no adverse alteration in groups of experimental animals on administration of multi-fruit wine (with or without additives) hence it can be suggested for therapeutic purposes associated with the maintenance of kidney and liver function. Further research on the histopathology will help elucidate these facts.

\section{References}

[1] J. Robinson, The Oxford companion to wine (New York: Oxford University Press, 2006)

[2] J. Feher, G. Lengyel, and A. Lugasi, Cultural history of wine, the theoretical background of wine therapy, Orvosi Hetilap, 146, 2005, 2635-2639.

[3] E.B. Rimm, A. Klatsky, D. Grobbee, and M.J. Stampfer, Review of moderate alcohol consumption and reduced risk of coronary heart disease: Is the effect due to beer, wine, or spirits, British Medical Journal, 312, 1996, 731-736.

[4] A.S. Hansen, P. Marckmann, L.O. Dragsted, I.L. Finne Nielsen, S.E. Nielsen, and M. Gronbaek, Effect of red wine and red grape olive oil antioxidants: A synergistic effect of components of the Mediterranean diet, Journal of American College of Nutrition, 27, 2005, 448-453.

[5] M.L. Lindberg and E.A. Amsterdam, Alcohol, wine, and cardiovascular health, Clinical Cardiology 31, $2008,347-351$.

[6] J.C. Ruf, Overview of epidemiological studies on wine, health and mortality, Drugs Under Experimental and Clinical Research, 29 (5-6), 2003, 173-179.

[7] G.M. Halpern, A celebration of wine: wine is medicine, Inflammopharmacology, 16, 2008, $240-244$.

[8] A. Saremi, and R. Arora, The cardiovascular implications of alcohol and red wine, American Journal of Therapeutics, 15(3), 2008, 265-277.

[9] S.M. Tsunoda, R.Z. Harris, U. Christians, R.L. Velez, R.B. Freeman, L.Z. Benet, and A. Warshaw, Red wine decreases cyclosporine bioavailability, Clinical Pharmacology and Therapeutics, 70, 2001, 462-467.

[10] A. Puja, F. Halaweish, and C. Dwivedi, Antioxidant effects and drug interactions of resveratrol present in wine, Journal of Wine Research, 18, 2007, 59-71.

[11] D.G. Bailey, G.K. Dresser, and J.R. Bend, Bergamottin, lime juice, and red wine as inhibitors of cytochrome P450 3A4 activity: Comparison with grapefruit juice, Clinical Pharmacology and Therapeutics, 73, 2003, 529-537.

[12] D. Mezzano, Distinctive effects of red wine and diet on haemostatic cardiovascular risk factors, Biological Research, 37, 2004, 217224.

[13] F. Jacobs, Making wine from pineapple. (Owerri: Ihem Davis Press, 2001).

[14] A.A. Asuk, I.B. Umoh, M.U. Eteng, C.O. Jayeola, and E.O. Akpanyung, Production, characterization and safety of wine obtained from a blend of tomato, almond, orange, lemon and African star apple extract, Annals of Biological Research, 2(5), 2011, 492-503

[15] M. Zimmermann, Ethical guidelines for investigation of experimental pain unconscious animals, Pain, 16, 1983, 109-110.

[16] Australian Government Department of Health and Ageing (AGDHA), Standard drinks guide (Woden, Canberra, 2009)

[17] N.W. Tietz, Clinical guide to laboratory tests (Philadelphia, USA: W.B Saunders, 1995)

[18] A.C. Guyton, and J.E. Hall, Textbook of medical physiology (Philadelphia: W. B. Saunders, 2004)

[19] G.E. Duncan, S.S. Moy, J.A. Lieberman, and B.H. Koller, Typical and antipsychotic drug effect on locomotor hyper activity and deficits in sensoriortor grafting in genetic model of MDA receptor hypofunction, Pharmacology and Biochemical Bevahiour, 10(8), $1994,481-491$

[20] K. Dasofunjo, O.F.C. Nwodo, O.E. Yakubu, R. Ejoba, R.U. Ukpanukpong, S.S. Ipav, M.N. Ugwu, A.I. Okafor, and S.L. Girgi, Hepatoprotective effect of Piliostigma thonningii leaves on male wistar rats, Asian journal of Plant Science and Research 3(4), 2013, 13-17

[21] D.E. Frigo, B.N. Duong, L.I. Melnik, L.S. Sherif, B.M. Collins-Burow, D.K. Pace, J.A. McLanchlan, and M.E. Burrow, Flavonoid phytochemicals regulate activator proteins -1 signal transduction pathway in endometrial and kidney stable cell lines, Journal of Nutrition, 132, 2002, 1848-1853.

[22] M.M.Y. Tin, C. Cho, K. Chan, A.E. James, and J.K.S. Ko, Astragulus saponins induce growth inhibition and apoptosis in human colon cancer cells and tumor xenograft, Carcinogenesis, 28 (6), 2007, 1347-1355. 